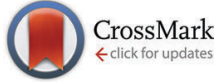

Cite this: Phys. Chem. Chem. Phys., 2016, 18, 12662

Received 28th January 2016, Accepted 7th April 2016

DOI: $10.1039 / c 6 c p 00634 \mathrm{e}$

www.rsc.org/pccp

\title{
Ozone uptake on glassy, semi-solid and liquid organic matter and the role of reactive oxygen intermediates in atmospheric aerosol chemistry $\dagger$
}

\author{
Thomas Berkemeier, ${ }^{\star a}$ Sarah S. Steimer, ${ }^{\text {bc }}$ Utrich K. Krieger, ${ }^{c}$ Thomas Peter, ${ }^{c}$ \\ Ulrich Pöschl, ${ }^{a}$ Markus Ammann ${ }^{\mathrm{b}}$ and Manabu Shiraiwa*a
}

\begin{abstract}
Heterogeneous and multiphase reactions of ozone are important pathways for chemical ageing of atmospheric organic aerosols. To demonstrate and quantify how moisture-induced phase changes can affect the gas uptake and chemical transformation of organic matter, we apply a kinetic multi-layer model to a comprehensive experimental data set of ozone uptake by shikimic acid. The bulk diffusion coefficients were determined to be $10^{-12} \mathrm{~cm}^{2} \mathrm{~s}^{-1}$ for ozone and $10^{-20} \mathrm{~cm}^{2} \mathrm{~s}^{-1}$ for shikimic acid under dry conditions, increasing by several orders of magnitude with increasing relative humidity $(\mathrm{RH})$ due to phase changes from amorphous solid over semisolid to liquid. Consequently, the reactive uptake of ozone progresses through different kinetic regimes characterised by specific limiting processes and parameters. At high $\mathrm{RH}$, ozone uptake is driven by reaction throughout the particle bulk; at low $\mathrm{RH}$ it is restricted to reaction near the particle surface and kinetically limited by slow diffusion and replenishment of unreacted organic molecules. Our results suggest that the chemical reaction mechanism involves long-lived reactive oxygen intermediates, likely primary ozonides or $\bigcirc$ atoms, which may provide a pathway for self-reaction and catalytic destruction of ozone at the surface. Slow diffusion and ozone destruction can effectively shield reactive organic molecules in the particle bulk from degradation. We discuss the potential non-orthogonality of kinetic parameters, and show how this problem can be solved by using comprehensive experimental data sets to constrain the kinetic model, providing mechanistic insights into the coupling of transport, phase changes, and chemical reactions of multiple species in complex systems.
\end{abstract}

\section{Introduction}

Organic compounds are ubiquitous in the earth's atmosphere and constitute a major fraction of atmospheric particulate matter. ${ }^{1-3}$ Finely dispersed submicron particles affect climate by scattering sunlight and serving as nuclei for cloud droplets and ice crystals ${ }^{4}$ and play a key role in air quality and public health by reducing visibility and posing adverse health effects. ${ }^{5,6}$ Most organic aerosols arise from oxidation of volatile organic compounds followed by condensation of oxidation products, so-called secondary organic aerosols (SOA). ${ }^{2,3,7}$ After formation, organic aerosols are still subject to chemical processing

\footnotetext{
${ }^{a}$ Max Planck Institute for Chemistry, Multiphase Chemistry Department, 55128 Mainz, Germany. E-mail: t.berkemeier@mpic.de, m.shiraiwa@mpic.de

${ }^{b}$ Paul Scherrer Institute, Laboratory of Environmental Chemistry, 5232 Villigen PSI, Switzerland

${ }^{c}$ ETH Zurich, Institute for Atmospheric and Climate Science, 8092 Zurich, Switzerland

$\dagger$ Electronic supplementary information (ESI) available. See DOI: 10.1039/ c6cp00634e
}

by reactive trace gases such as ozone,${ }^{8,9}$ ammonia, ${ }^{10}$ the hydroxyl $l^{11-13}$ or nitrate radical, ${ }^{14,15}$ influencing chemical composition ${ }^{16-18}$ and particle size distribution, ${ }^{19}$ and hence, affecting hygroscopicity, ${ }^{20-22}$ viscosity, ${ }^{23}$ gas-particle partitioning, ${ }^{24-26}$ radiative properties, ${ }^{27}$ and toxicity. ${ }^{28}$ The rate of chemical reactions occurring in aerosol particles depends strongly on their phase state, ${ }^{8-11,18,29}$ which varies from liquid to solid depending on composition $^{30-32}$ and ambient conditions such as temperature and relative humidity. ${ }^{33-39}$ Accordingly, diffusivity of organic molecules $^{40}$ and trace gases penetrating the organic matrix ${ }^{41-44}$ decreases significantly under cold or dry conditions.

Accurate description of the multiphase reaction kinetics of these systems is vital for understanding the rates at which compounds degrade and oxidants are consumed. Kinetic models commonly evaluate single steps that may limit reaction rate such as mass transfer or chemical reaction. Classical resistor models are computationally inexpensive, but only describe certain aspects of the reaction system in distinct limiting cases. ${ }^{45,46}$ These models have difficulty in describing systems which are driven by multiple rate-limiting processes or transition between limiting cases. ${ }^{47}$ 
Hence, the important subset of cases where both the bulk material and the trace gas show diffusion limitation ("counter-diffusion case") cannot be properly described.

Kinetic flux models resolve this problem by tracking reactant concentration as a function of depth, ${ }^{48-51}$ which leads to a better description of the processing of organic material in the atmosphere. ${ }^{8,12,15}$ However, they are computationally more expensive and rely on a set of kinetic parameters of which not all are directly accessible by experiment. Due to the high number of input parameters, kinetic flux models applied to small data sets are usually not fully constrained, leaving large flexibility in the possible range of input parameters yielding the same or similar model output. ${ }^{12,47}$ The two possible solutions to this problem are (i) reduction of the kinetic input parameter set and thus simplification of the kinetic model and loss of information or (ii) extension of the dimensions of the experimental input data set. Added dimensions can be additional experimental observables (e.g. reactant concentrations in gas and particle phase, viscosity, system size, refractive indices) or can be varied environmental conditions (reactant concentrations, system size, temperature, relative humidity) or simply an extended observation time scale to encompass more rate-limiting processes. ${ }^{47,52}$ A kinetic parameter can only be determined if a related process affects the measured quantity. Care must be taken in case parameters depend on environmental conditions (e.g. bulk diffusion coefficients depend on both $\mathrm{RH}$ and temperature separately).

These criteria of a wide range of experimental dimensions are fulfilled in a recent study by Steimer et al., who investigated ozonolysis of shikimic acid as model system for chemical processing of organic aerosols. ${ }^{53}$ The cyclohexene derivative shikimic acid contains a single double bond that serves as target for ozone. Due to the closed ring structure, ozonolysis does not lead to fragmentation and thus volatilization of the oxidation products. The structural formula of shikimic acid is displayed in Fig. 1A. Pure shikimic acid exhibits a glassy solid phase state with a glass transition temperature of $327 \mathrm{~K} .{ }^{54}$ Due to the plasticizing effect of water, shikimic acid is expected to cover the full range of (semi-)solid phase states at atmospherically relevant RHs. The experimental study by Steimer et al. clearly demonstrated the limitations of classical methods for analysis of heterogeneous kinetics, which motivates the application of the kinetic multi-layer model for aerosol surface and bulk chemistry $(\mathrm{KM}-\mathrm{SUB})^{49}$ to the kinetic data set in this study. In order to cope with the extended set of kinetic parameters of the kinetic flux model, we apply a global optimization method including a genetic algorithm to find an optimal correlation between model and experiment.

\section{Methods}

The kinetic experiments have been reported in detail by Steimer et al. and will be described only briefly in the following. ${ }^{53}$ Experiments were performed in an atmospheric pressure coated wall flow reactor ( $48 \mathrm{~cm}$ length, $1.2 \mathrm{~cm}$ inner diameter) with long reaction times and atmospherically relevant oxidant
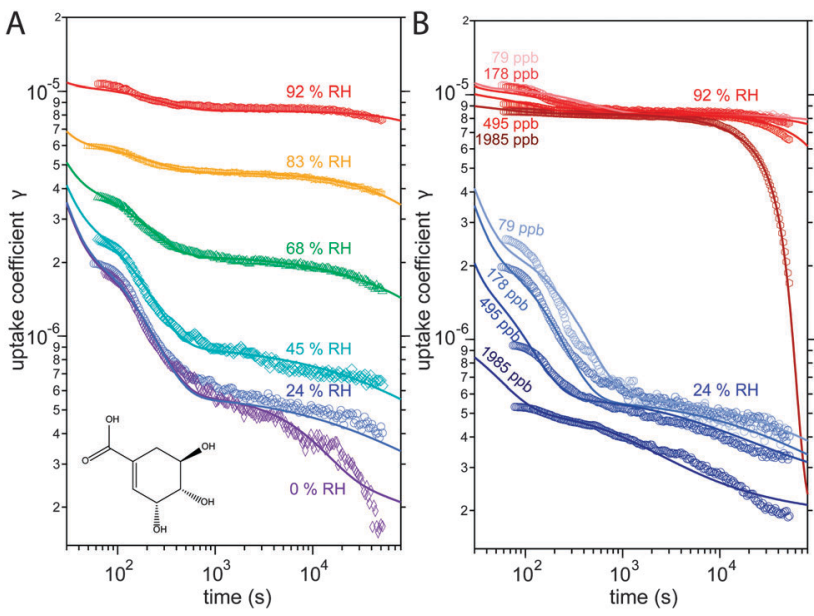

Fig. 1 Observed (markers) and modelled (lines) uptake coefficients of ozone $\gamma$ onto a thin film of shikimic acid as a function of exposure time. (A) Uptake coefficients at $178 \mathrm{ppb}$ ozone gas phase concentration $\left[\mathrm{O}_{3}\right]_{\mathrm{g}}$ at different relative humidities of $0,24,45,68,83$, and $92 \%$. The structural formula of shikimic acid is displayed in the left bottom corner. (B) Uptake coefficients at $24 \% \mathrm{RH}$ (blue solid lines) and $92 \% \mathrm{RH}$ (red solid lines) with different $\left[\mathrm{O}_{3}\right]_{\mathrm{g}}$ of $79,178,495$, and $1985 \mathrm{ppb}$.

concentrations as detailed. The temperature in the reactor was held constant by a thermostat-controlled cooling jacket and $\mathrm{RH}$ was adjusted by directing gas flows through tempered water reservoirs.

Measurements were performed at an $\mathrm{O}_{3}$ concentration of $178 \mathrm{ppb}$ at 6 different relative humidities: 0, 24, 45, 69, 83 and $92 \%$ RH. At 24 and 92\%, measurements were conducted at three additional $\mathrm{O}_{3}$ concentrations of 89, 495 and $1985 \mathrm{ppb}$, giving a total of 12 distinct experimental conditions. The measurement results are ozone uptake coefficients $\gamma$, which represent the probability that ozone molecules colliding with a surface are subsequently taken up by the condensed phase. ${ }^{55}$ The experimental data is shown Fig. 1.

\subsection{Kinetic model}

We use the kinetic multi-layer model of aerosol surface and bulk chemistry, KM-SUB, which provides a depth-resolved description of mass transport and chemical reaction in aerosol particles and surface films. ${ }^{49}$ KM-SUB resolves the following processes explicitly: gas-phase diffusion, adsorption and desorption, surface-bulk exchange, bulk diffusion of trace gas (X) and bulk material (Y) as well as chemical reactions at the surface and in the bulk. The following three reaction pathways are considered for ozone loss in the KM-SUB representation of the reaction system: a bimolecular surface layer reaction between adsorbed ozone and surface-exposed shikimic acid (SLR1), a bulk reaction between both reactants (BR) and the self-reaction of two ozone molecules adsorbed to the surface (SLR2). Secondary reactions involving oxidation products are neglected for simplicity.

For this study, several modifications have been applied to the original KM-SUB model as outlined below. The kinetic behaviour of a reaction system is described in this modified version of KM-SUB by the thirteen kinetic parameters given in 


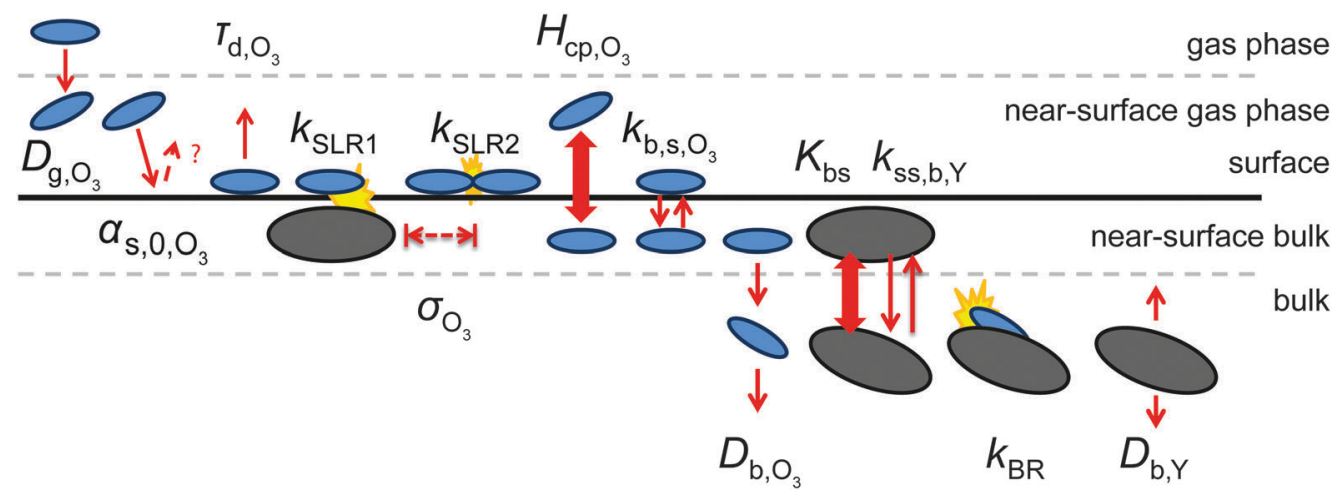

Fig. 2 Schematic representation of the input parameters and processes of KM-SUB in this study. Trace gas and reactive bulk molecules are represented by blue and black ellipses, respectively. Simple red arrows denote transport; broad double-headed arrows indicate partitioning and yellow shapes represent chemical reactions. The parameters include the gas-phase diffusivity $\left(D_{\mathrm{g}, \mathrm{O}_{3}}\right)$, surface accommodation coefficient $\left(\alpha_{\mathrm{s}, 0, O_{3}}\right)$, desorption lifetime $\left(\tau_{\mathrm{d}, \mathrm{O}_{3}}\right)$, adsorption cross section $\left(\sigma_{\mathrm{O}_{3}}\right)$ and the Henry's law coefficient $\left(\mathrm{H}_{\mathrm{CP}, \mathrm{O}_{3}}\right)$ of ozone; the surface reaction rates $\left(k_{\mathrm{SLR} 1}\right.$ and $\left.k_{\mathrm{SLR} 2}\right)$, the bulk reaction rate $\left(k_{\mathrm{BR}}\right)$; the surface-bulk transport rates of ozone $\left(k_{\mathrm{b}, \mathrm{s}, \mathrm{O}_{3}}\right)$ and shikimic acid $\left(k_{\mathrm{ss}, \mathrm{b}, \mathrm{Y}}\right)$, the surface equilibrium constant of shimic acid $\left(K_{\mathrm{bs}}\right)$ and the bulk diffusion coefficients of ozone $\left(D_{\mathrm{b}, \mathrm{O}_{3}}\right)$ and shikimic acid $\left(D_{\mathrm{b}, \mathrm{Y}}\right)$.

Table S1 (ESI $\dagger$ ). Fig. 2 illustrates the microscopic representations of the processes covered with KM-SUB in this study.

Similar to previous studies ${ }^{26,47}$ a near-surface gas-phase layer (extending one mean free path $\lambda_{\mathrm{x}}$ of the gas molecules from the surface) has been added to explicitly resolve diffusion of gas molecules to the surface. The gas phase diffusion flux $J_{\text {diff }}$ from the flow tube centre with far from surface trace gas concentration $[\mathrm{X}]_{\mathrm{g}}$ to the near-surface gas phase layer with concentration $[\mathrm{X}]_{\mathrm{gs}}$ is described following the Knopf-PöschlShiraiwa approach for gas phase diffusion in cylindrical reactors. ${ }^{56}$

$$
J_{\text {diff }}=\frac{3.66 D_{\mathrm{g}, \mathrm{X}}\left([\mathrm{X}]_{\mathrm{g}}-[\mathrm{X}]_{\mathrm{gs}}\right)}{\left(d-2 \lambda_{\mathrm{X}}\right)},
$$

where $D_{\mathrm{g}, \mathrm{X}}$ is the gas phase diffusion coefficient and $d$ is the tube radius. Since the gas phase oxidant concentration decreases over the length of the flow tube reactor, we assume an effectively lowered $[\mathrm{X}]_{\mathrm{g}}$ that is determined by the dynamic equilibrium between loss to the flow tube walls and resupply by gas flow with volumetric flow rate $\phi$.

$$
\frac{\mathrm{d}[\mathrm{X}]_{\mathrm{g}}}{\mathrm{d} t}=\frac{\phi}{V_{\mathrm{gs}}}\left([\mathrm{X}]_{\mathrm{g}, 0}-[\mathrm{X}]_{\mathrm{g}}\right)-J_{\text {diff }} \frac{A_{\mathrm{gs}}}{V_{\mathrm{gs}}}
$$

$A_{\mathrm{gs}}$ and $V_{\mathrm{gs}}$ are the surface area and volume of the near-surface gas phase layer, respectively.

Bulk diffusion is treated as first order process, following Fick's first law of diffusion. ${ }^{55}$ While Fickian diffusion is a continuum approach that strictly only applies if molecular motion can be described by random motion of an ensemble of molecules, continuum conditions can always be generated by choosing sufficiently small layer sizes. At low diffusivity and high reactivity, however, the spatial extension of diffusion gradients approaches the molecular length scale, which can induce effects related to coarseness of matter in reactiondiffusion systems. To consider these effects, we chose a lower limit for bulk layer thickness of $0.3 \mathrm{~nm}$, congruent with previous work. ${ }^{57}$
In contrast to the original KM-SUB, the quasi-stationary surface layer (ss) has a certain extent into the particle and hence also constitutes the near-surface bulk. The surface concentration of bulk material (i.e., shikimic acid), $[\mathrm{Y}]_{\mathrm{ss}}$, can be interpreted as concentration of reactive sites (i.e. $\mathrm{C}-\mathrm{C}$ double bonds) accessible by surface-adsorbed molecules. This entity depends crucially on molecular structure and orientation: molecules may spread out at the surface or form a densely packed monolayer. The reactive site of a molecule in the surface layer might not be facing upwards but be directed away from the surface and may not undergo a surface layer-type reaction. ${ }^{58}$ Thus, we define the surface-accessible fraction of reactive sites by defining a surface equilibrium constant $K_{\mathrm{bs}}$ that relates an equilibrium near-surface bulk concentration $[\mathrm{Y}]_{\mathrm{b} 1 \text {,eq }}$ to an equilibrium surface concentration $[\mathrm{Y}]_{\mathrm{ss}, \mathrm{eq}} \cdot K_{\mathrm{bs}}$ can be interpreted as a depth to which surface-adsorbed ozone molecules can still react with near-surface bulk molecules without undergoing a phase transfer into the bulk phase.

$$
K_{\mathrm{bs}}=\frac{[\mathrm{Y}]_{\mathrm{ss}, \mathrm{eq}}}{[\mathrm{Y}]_{\mathrm{b} 1, \mathrm{eq}}}
$$

The RH-dependent initial bulk concentration $[\mathrm{Y}]_{\mathrm{b}, 0}$ is derived from hygroscopicity measurements in an electrodynamic balance. ${ }^{59}$ The use of $K_{\text {bs }}$ enables to consider ordered surface orientations ${ }^{58}$ or increased surface concentrations of surface-active components such as surfactants. This equilibrium is created by relating the rate constants for surface-to-bulk transport, $k_{\mathrm{ss}, \mathrm{b}, \mathrm{Y}}$, and vice vers $a, k_{\mathrm{b}, \mathrm{ss}, \mathrm{Y}}$, also considering the partial coverage of surface sites $\theta_{\text {ss. }}$

$$
k_{\mathrm{b}, \mathrm{ss}, \mathrm{Y}}=k_{\mathrm{ss}, \mathrm{b}, \mathrm{Y}}\left(1-\theta_{\mathrm{ss}}\right) K_{\mathrm{bs}}
$$

As modification to the original KM-SUB, the surface exchange rates of $\mathrm{X}$ and $\mathrm{Y}$ have been decoupled from the respective bulk diffusion coefficients. $k_{\mathrm{b}, \mathrm{ss}, \mathrm{Y}}$ and $k_{\mathrm{s}, \mathrm{b}, \mathrm{X}}$ are hence used as separate input parameters. Surface molecules could be either more mobile $^{60}$ (as in quasi-liquid surface layers of solids) or more 
immobile than molecules in the bulk of a sample (e.g. through high surface tension). Analogously, molecules may exchange quickly between surface and near-surface bulk or be locked in either one of both positions, which should be represented by the surface-bulk exchange rates. The total number of surface adsorption sites, $N_{\max }$, is approximated as the inverse of an effective molecular cross section of $\mathrm{O}_{3}, \sigma_{\mathrm{O}_{3}}$. In the original KM-SUB approach, $\sigma_{\mathrm{O}_{3}}$ is assumed to be equivalent to the geometrical size of $\mathrm{O}_{3}$. However, $\mathrm{O}_{3}$ molecules might occupy a larger area on the surface than their geometrical size, or the density of stable adsorption sites might be lower than the closest possible packing of $\mathrm{O}_{3}$. To account for such aspect, $\sigma_{\mathrm{O}_{3}}$ is used as a fit parameter in this study. The effective molecular cross section of shikimic acid, $\sigma_{\mathrm{Y}}$, was assumed to be $3.34 \times 10^{-15} \mathrm{~cm}^{2}$, limiting its surface concentration to a maximum of $[\mathrm{Y}]_{\mathrm{ss}, \max }=3 \times 10^{14} \mathrm{~cm}^{-2}$. A summary of all input parameters for KM-SUB is given in Table S1 (ESI $\dagger$ ).

\subsection{Global optimization algorithm}

In order to obtain a common kinetic parameter set describing all experimental data sets, we used a global fitting method combining a uniformly-sampled Monte-Carlo (MC) search with a genetic algorithm (GA). ${ }^{12,47}$ In the MC search, kinetic input parameters for KM-SUB were varied randomly within individual bounds. All measurements were fitted simultaneously by the model and the correlation between modelled uptake coefficient $\gamma_{\bmod }(t)$ and experimentally determined uptake $\gamma_{\exp }(t)$ evaluated in a least-squares fashion. For each experimental data set $i$, the residual $r_{i}$ was calculated in log-space to account for the large range of $\gamma$ observed during the experiments.

$$
r_{i}=\frac{1}{f_{i}} \sqrt{\frac{1}{j_{i}} \sum_{i=1}^{n}\left(\log _{10}\left(\gamma_{\bmod }\left(t_{i}\right)\right)-\log _{10}\left(\gamma_{\exp }\left(t_{i}\right)\right)\right)^{2}}
$$

Each data set was weighted by its number of data points $j_{i}$ and by a weighting constant $f_{i}$ that accounts for scatter within each data set. In this study all data sets were weighted equally $\left(f_{i}=1 / 12\right)$. To ensure correlation between model and experiment over the entire time range, the experimental input data was spaced logarithmically in time. Finally, the tested parameter set is assessed by the sum of the single residuals $R=\sum r_{i}$. The globally best-fitting parameter sets, i.e. the sets with lowest $R$, are fed into the starting population of a genetic algorithm (GA, Matlab ${ }^{\circledR}$ Global Optimization Toolbox) in which they are optimised by processes mimicking survival, recombination and mutation in evolutionary biology. To ensure diversity within the pool of parameter sets and to counteract the sampling bias from shallow local minima, the same number of random KM-SUB input parameter sets was added to the starting population. In the GA step, the same parameter boundaries were used as in the preceding MC step. The optimization was stopped when the population was homogeneous and thus the increase in correlation with the experimental data ceased. Multiple optimizations were conducted to ensure that using different starting parameter sets would not lead to a better correlation and a global minimum was reached. The bulk diffusion coefficients, $D_{\mathrm{b}, \mathrm{O}_{3}}$ and $D_{\mathrm{b}, \mathrm{Y}}$, are expected to vary with relative humidity, ${ }^{8}$ so for each humidity, an individual coefficient was assigned. We also found that varying the rates of surface-bulk transport, $k_{\mathrm{ss}, \mathrm{b}, \mathrm{Y}}$ and $k_{\mathrm{b}, \mathrm{s}, \mathrm{O}_{3}}$, the Henry's law solubility coefficient $H_{\mathrm{cp}, \mathrm{O}_{3}}$ and the surface equilibrium constant $K_{\mathrm{bs}}$ as a function of $\mathrm{RH}$ leads to a much better correlation to the experimental data. It was assumed that each parameter is a monotonic function of $\mathrm{RH}$, which reduced the input parameter space dramatically and led to much faster convergence in the MCGA fitting. For all other input parameters, RH dependence was neglected and the same values for the input parameters are used for all experimental conditions. The full list of kinetic parameters obtained by fitting KM-SUB to the 12 experimental data sets is given in Table S2 (ESI $\dagger$ ). Some kinetic parameters remained fixed during the fitting process. The gas-phase diffusion coefficient of ozone, $D_{\mathrm{g}, \mathrm{O}_{3}}$, was measured to be $0.14 \mathrm{~cm}^{2} \mathrm{~s}^{-1} \cdot{ }^{61}$ Kinetic limitation by surface accommodation is not expected in the shikimic acid ozonolysis reaction system with low uptake coefficients $\left(<10^{-5}\right)$, hence, $\alpha_{\mathrm{s}, 0}$ was set to 0.5 based on previous studies of kinetic modelling ${ }^{8,62}$ and molecular dynamic simulations. ${ }^{63-65}$

In total, we varied 11 parameters, 6 of which were allowed to increase or decrease monotonically over 6 steps in relative humidity. Thus, a total of 41 distinct parameter values were obtained during optimization to the experimental data. Optimization of such a large parameter set is computationally expensive and only feasible on a computer cluster for models like KM-SUB. In a typical optimization 10 million single KM-SUB model runs were performed, requiring about 2 days of computation time on 120 CPUs. After global optimization, a 1D local optimization (golden cut search) was performed to check for local convergence. In this step, the monotonicity restraint of the parameter's RH dependence was not applied. To decrease computation time, the initial global fit was conducted without gas-phase diffusion and gas-phase loss corrections, which accelerated computation by a factor of 10 . The obtained result was then optimised locally to re-fit to the experimental data including the additional minor correction terms.

\section{Results and discussion}

\subsection{Uptake data and global optimization results}

The experimental uptake coefficients ${ }^{53}$ and the corresponding KM-SUB results obtained with the MCGA algorithm are shown in Fig. 1. Panel A shows a clear increase in $\gamma$ upon increase in $\mathrm{RH}$, consistent with recent experimental data. ${ }^{8,32}$ In panel $\mathrm{B}$, the effect of changing gas-phase ozone concentration is displayed for $24 \% \mathrm{RH}$ (blue lines) and $92 \% \mathrm{RH}$ (red lines): at high $\left[\mathrm{O}_{3}\right]_{\mathrm{g}}$, a lower $\gamma$ is observed. The correlation between model and experiment is high overall, achieving a low total residual $R$ of 0.020 according to eqn (5).

The plot of uptake data against time reveals a step profile in which several plateaus can be identified. The first prominent plateau in the experimental data occurs at around $100 \mathrm{~s}$ and transitions into a second plateau at around $1000 \mathrm{~s}$. In the low $\mathrm{RH}$ data we can also find signs for a third plateau at $\sim 5 \times 10^{4} \mathrm{~S}$ reaction time. This can be understood by the model results 

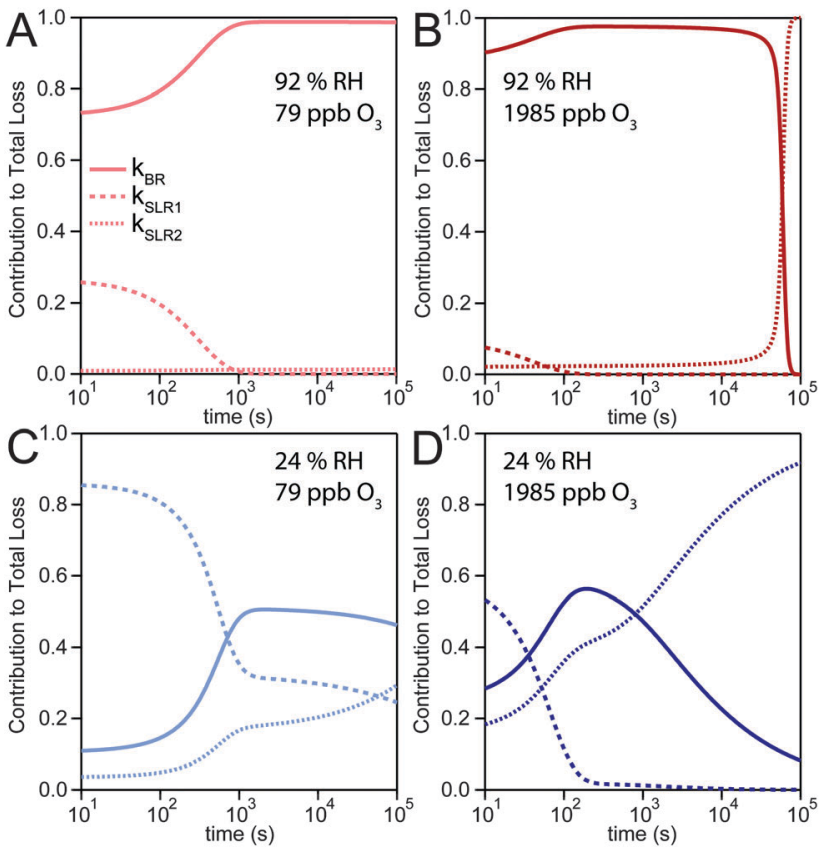

Fig. 3 Contribution of three reaction pathways to the total loss rate of ozone: a bulk reaction between ozone and shikimic acid (BR, solid lines), a bimolecular surface layer reaction between ozone and shikimic acid (SLR1, dashed lines), and the self-reaction of two ozone molecules adsorbed to the surface (SLR2, dotted lines). Modelling results are shown for two relative humidities and two ozone concentrations: (A) $92 \% \mathrm{RH}$, $79 \mathrm{ppb} \mathrm{O}_{3}$, (B) $92 \% \mathrm{RH}, 1985 \mathrm{ppb} \mathrm{O}$, (C) $24 \% \mathrm{RH}, 79 \mathrm{ppb} \mathrm{O}_{3}$, (D) $24 \% \mathrm{RH}$, $1985 \mathrm{ppb} \mathrm{O}_{3}$

shown in Fig. 3, which details the contribution of the three pathways of ozone loss (SLR1, SLR2, BR) to the total ozone loss at 24 and $92 \% \mathrm{RH}$ for 79 and $1985 \mathrm{ppb}\left[\mathrm{O}_{3}\right]_{\mathrm{g}}$ in the kinetic model.

Until around $1000 \mathrm{~s}$ reaction time, surface reaction between ozone and shikimic acid (SLR1, dashed lines) contributes significantly to the overall ozone loss under all conditions. We thus term the initial plateau the surface reaction plateau. This is consistent with previous resistor model descriptions and justified by its inverse $\mathrm{O}_{3}$ concentration dependence. ${ }^{53}$ The integral uptake within this period corresponds roughly to a monolayer of shikimic acid. ${ }^{53}$ The relative contribution of SLR1 is highest at low $\left[\mathrm{O}_{3}\right]_{\mathrm{g}}$ and dry $\mathrm{RH}$. However, the absolute rate of surface reaction is almost independent of $\mathrm{RH}$ and rather a function of $\left[\mathrm{O}_{3}\right]_{\mathrm{g}}$.

The contribution of SLR1 becomes very low after $1000 \mathrm{~s}$ due to depletion of shikimic acid at the surface except in the case of low $\left[\mathrm{O}_{3}\right]_{\mathrm{g}}$ and low $\mathrm{RH}$ (panel $\mathrm{C}$ ), where surface reaction remains substantial as transport of bulk material $\mathrm{Y}$ to the surface is sufficiently fast and bulk reaction sufficiently slow to maintain a high quasi-stationary concentration of surface-exposed molecules. After $1000 \mathrm{~s}$, bulk reaction (BR, solid lines) dominates the overall uptake for the majority of the investigated cases. Thus, the second plateau in the experimental uptake data can be termed as the bulk reaction plateau. The model result again confirms the assignment of this kinetic regime based on qualitative arguments with the resistor model. ${ }^{53}$ Self-reaction between two ozone molecules at the surface (SLR2, dotted lines) is present at all times and shows a high relative contribution when the overall ozone uptake is low $\left(\gamma<\sim 10^{-6}\right)$. When the bulk material is used up or strongly shielded by unreactive product, SLR2 will dominate the ozone loss, creating a third plateau on the reaction coordinate, the self-reaction plateau. Note that this case cannot be introduced into a classical resistor model. ${ }^{53}$ At lower $\mathrm{RH}$, model and experiment deviate slightly at reaction times $>2 \times 10^{4} \mathrm{~s}$. This data might however be influenced by a drift of the baseline concentration of ozone (see discussion in ref. 53). This is evident from the curvature of the experimental data after $2 \times 10^{4} \mathrm{~s}$ : while some of the uptake data at low $\mathrm{RH}$ are right-bent (drop in $\gamma$ accelerates) as is especially pronounced in the $0 \% \mathrm{RH}$ data set, others are left-bent (drop in $\gamma$ halts) as can be seen in the $495 \mathrm{ppb}$ and $1985 \mathrm{ppb}$ data set at $24 \% \mathrm{RH}$.

The 1985 ppb data set at 92\% RH (dark red markers in Fig. 1) shows an important feature that is fully captured by the KM-SUB model: due to fast reaction in the liquid film at high $\mathrm{RH}$ and a high ozone concentration, shikimic acid is depleted in the flow reactor which causes a steep drop in $\gamma$ after about $10^{4} \mathrm{~s}$ of ozone exposure, providing an important constraint on the magnitude of the bulk reaction rate coefficient, $k_{\mathrm{BR}}$.

\subsection{Kinetic regimes of the reaction system}

In addition to characterization of the three major pathways of ozone loss, a full determination of the kinetic regime of a reaction system is required for identification of the physical or chemical processes limiting overall gas uptake. ${ }^{47,66} \mathrm{We}$ characterise the regime by three classification parameters: ${ }^{20}$ the contribution of surface reaction to the total chemical loss rate (STLR), the saturation ratio assessing the supply of reactants from the gas phase (SR) and a mixing parameter assessing the extent of spatial heterogeneity in the particle phase (MP). The kinetic regimes and limiting cases defined by these criteria can be visualised in a "kinetic cube", in which each axis corresponds to one of the three classification parameters. At the extremes of the classification parameters (vertices of the kinetic cube), we find the limiting cases usually used in kinetic modelling studies such as a bulk reaction with well-mixed reactants $\left(\mathrm{B}_{\mathrm{rx}}\right)$ or a surface reaction limited by diffusion of bulk material to the surface $\left(\mathrm{S}_{\mathrm{bd}}\right) .{ }^{47}$ For these cases we assign termsymbol like identification symbols that reveal the predominant reaction location ("G"'as phase, "S"urface or "B"ulk) and the limiting process (rx: chemical reaction, bd: bulk diffusion, mt: mass transfer, gd: gas diffusion) of the reaction system. A more detailed description of the concept of kinetic regimes and the kinetic cube can be found in Berkemeier et $a l^{47}$ and in the ESI $\dagger$ (Section A).

A detailed look into the kinetic regime of the shikimic acid ozone reaction system is provided in Fig. 4. Fig. 4A shows the temporal evolution of $\gamma$ at $178 \mathrm{ppb}$ ozone and 24\% $\mathrm{RH}$ and highlights five distinctive points (yellow circles) on the reaction coordinate. Fig. 4B outlines the corresponding evolution of the kinetic regime in the kinetic cube. Fig. 4C shows a projection of the top plane of the kinetic cube (shaded area in panel B) and compares with the corresponding experiment at $92 \% \mathrm{RH}$ to outline the differences in the kinetic regimes at higher $\mathrm{RH}$. 

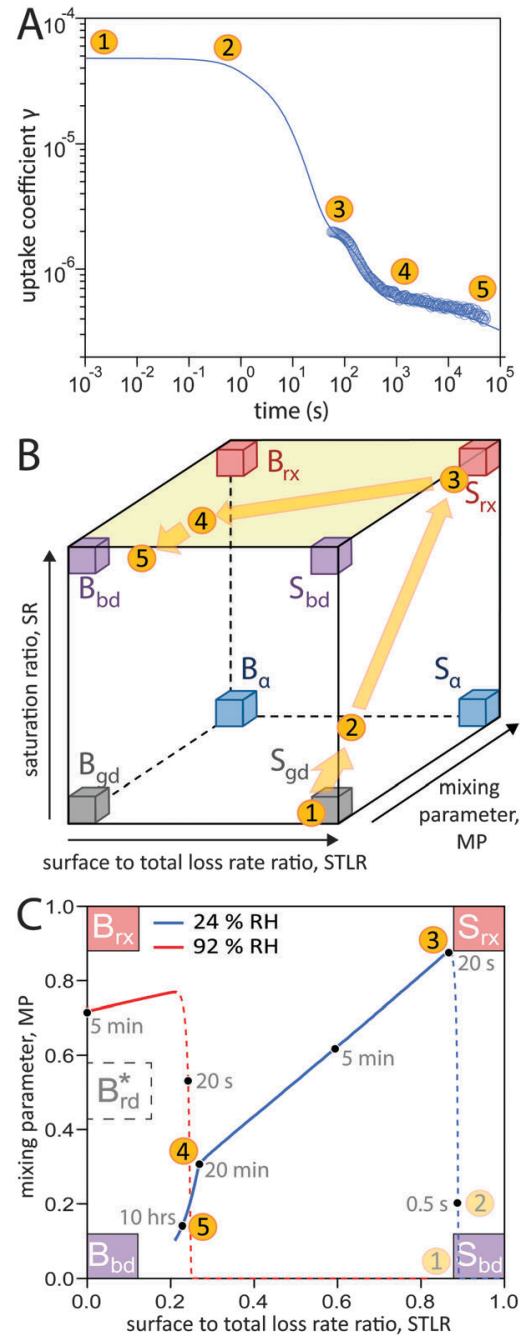

Fig. 4 Temporal evolution of the reaction system's kinetic regime. (A) 5 characteristic points on the reaction coordinate. (B) These points lie on a trajectory through the kinetic cube, ${ }^{47}$ representing the change of the limiting process. From an initial gas-diffusion limited surface reaction $\left(\mathrm{S}_{\mathrm{gd}}\right)$, the system transitions into a reaction-rate limited surface reaction $\left(S_{r x}\right)$. After an inflection point, the system evolves towards a bulk-diffusion limited bulk reaction $\left(B_{b d}\right)$. (C) View at the top plane of the kinetic cube (marked green in panel b) with trajectories at $24 \% \mathrm{RH}$ (blue solid line) and $92 \% \mathrm{RH}$ (red solid line). Dashed lines are drawn while not in the top plane $(\mathrm{SR}<0.8)$.

At (1), the near-surface gas phase in the flow reactor is nearly depleted of $\mathrm{O}_{3}$ due to rapid adsorption of ozone, leading to an effective surface reaction in the absence of competition for adsorption sites. The ozone uptake is thus limited by gas-phase diffusion and falls into the limiting case $S_{\mathrm{gd}}$. At (2), the saturation ratio SR has increased due to accumulation of $\mathrm{O}_{3}$ molecules, possibly in the form of reactive oxygen intermediates, ${ }^{62}$ at the surface. This process continues until (3) when the adsorbed molecules have reached an effective/dynamic Langmuir adsorption equilibrium with the gas phase, reflected by a mixing parameter MP close to 1. At this stage, ozone uptake and loss of bulk material are limited by chemical reaction at the surface and the system falls into the limiting case $\mathrm{S}_{\mathrm{rx}}$. After $100 \mathrm{~s}$ of reaction time, depletion of surface-exposed bulk material causes a strong concentration gradient of shikimic acid in the bulk (decrease of MP) and bulk reaction becomes more important (decrease of STLR) as shown in Fig. 3. The system now strives towards a dynamic equilibrium at (4), in which bulk reaction and surface reaction are balanced (STLR 0.25) and bulk diffusion of both ozone and shikimic acid severely limits the reaction $(\mathrm{MP}<0.4)$. From that point, changes in the kinetic regime occur very slowly. Over the next hours, the diffusion flux of bulk material to the surface is gradually reduced, as bulk material is increasingly depleted in the near-surface bulk, indicated by a slow decrease in STLR and MP. At (5), the system is mainly limited by bulk diffusion, almost reaching the corresponding limiting case $\mathrm{B}_{\mathrm{bd}}$.

Panel C shows that at higher RH (red dashed and solid line), a slightly different route is taken through the kinetic cube compared to the dry state (blue dashed and solid line). The contribution of bulk reaction increases quickly after the start of ozone exposure due to fast bulk diffusion. The system quickly reaches its dynamic equilibrium at a much higher value of MP $(\sim 0.72)$. Ozone uptake is overall dominated by bulk reaction and diffusion and the system neither occupies a state where both reactants are well-mixed (i.e. $\mathrm{B}_{\mathrm{rx}}$ ), nor a state where the reaction is only constrained to the near-surface bulk (traditional reacto-diffusive case, $\mathrm{B}_{\mathrm{rd}}{ }^{*}$, ref. 47 ).

Even though in both cases described in Fig. 4C a dynamic equilibrium is reached after an initial phase of transient behaviour, the steady state behaviour is not compliant with standard limiting cases that can be described by analytical expressions of traditional resistor models. ${ }^{4-47,67,68}$ To our knowledge, no analytical expressions are available that describe a system driven by counter-diffusion of two reactive components ( $\mathrm{B}_{\mathrm{bd}}$ limiting case) as observed at low RH. While analytical expressions are well-known for the limiting cases $\mathrm{B}_{\mathrm{rx}}$ and $\mathrm{B}_{\mathrm{rd}}{ }^{*}$, there is no simple model for cases that lie between the two extremes, as observed at high $\mathrm{RH}$.

To illustrate these two types of diffusion behaviour, KM-SUB is used to create time-resolved depth profiles of bulk material as shown in Fig. 5. The analysis shows that under dry conditions shikimic acid is only degraded very close to the surface, in agreement with a study by Steimer et al. who showed no visible decay of bulk material using STXM microscopy. ${ }^{69}$ Even at $45 \%$ RH and after $10^{5}$ seconds reaction time, only the topmost $5 \%$ of the $200 \mathrm{~nm}$ film show significant loss in bulk material. In this case the reacto-diffusive length of ozone (black dashed lines), i.e. the effective depth over which reaction occurs, ${ }^{70}$ is merely $0.3 \%$ of the total film thickness. Upon increase in RH, elevated bulk diffusion coefficients lead to a larger reaction zone of ozone and shikimic acid as indicated by a larger reactodiffusive length and hence a broader band of reduced shikimic acid concentrations at the film surface (69\% RH and $83 \% \mathrm{RH})$. Note that at these intermediate humidities, no chemical gradients were detected using STXM microscopy as particles were already well-mixed at and above $52 \% \mathrm{RH}$. This disagreement is most likely due to the uncertainty in determining $D_{\mathrm{b}, \mathrm{Y}}$ caused by reaction products that might alter the diffusion coefficient inside the organic matrix as discussed in Section 3.3 below. At $92 \% \mathrm{RH}$, 


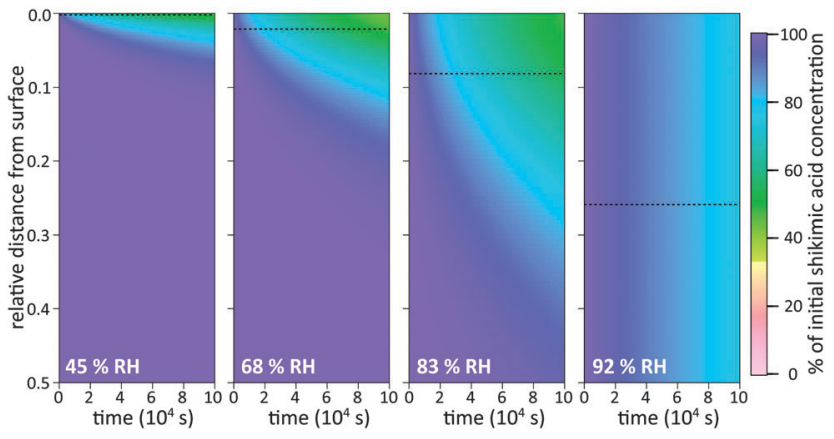

Fig. 5 Depth profiles of shikimic acid concentration in a film during exposure of $178 \mathrm{ppb}$ ozone as a function of time and relative humidity $(\mathrm{RH})$. The $y$-axis depicts the relative distance from the film surface $(0$ at the surface and 0.5 at half-way through the film). At $83 \% \mathrm{RH}$ and lower, the concentration of shikimic acid shows radial inhomogeneity. Upon increase in $\mathrm{RH}$ the penetration depth of ozone increases, here assessed by the classical reacto-diffusive length of ozone (black dotted line). At $92 \% \mathrm{RH}$, shikimic acid is perfectly mixed and decays homogeneously throughout the entire film.

shikimic acid is well-mixed in the model and ozone molecules reach almost the entire film depth, which is again consistent with STXM microscopy. These results on chemical gradients complement recent studies, which proposed the formation of chemical gradients in the oxidation of organic aerosol by $\mathrm{OH}^{12,44}$ and $\mathrm{NO}_{3} .{ }^{15}$ Our study shows chemical gradients even for the much slower reaction of organic aerosols with ozone.

\subsection{Kinetic parameters obtained from global optimization}

Fig. 6 shows the s-shaped humidity dependence of $D_{\mathrm{b}, \mathrm{O}_{3}}$ as determined by global optimization to the experimental data (solid circles). Such functional forms with a constant $D_{\mathrm{b}, \mathrm{O}_{3}}$ at low $\mathrm{RH}$ and a strong increase at medium $\mathrm{RH}$ are consistent with percolation theory, ${ }^{71}$ an approach commonly used to describe systems where small molecules percolate through a rigid matrix of larger molecules. ${ }^{8,19}$ Measurements of $D_{\mathrm{b}, \mathrm{H}_{2} \mathrm{O}}$ in shikimic acid by Steimer et al. ${ }^{59}$ (blue shadings) revealed overall higher diffusion coefficients and no s-shape of the $D_{\mathrm{b}, \mathrm{H}_{2} \mathrm{O}}$ curve. The $D_{\mathrm{b}, \mathrm{O}_{3}}$ curve however closely resembles the estimate of water diffusivity $\left(D_{\mathrm{b}, \mathrm{H}_{2} \mathrm{O}}\right)$ in $\alpha$-pinene secondary organic aerosol (SOA) of similar oxidation state (molecular $\mathrm{O} / \mathrm{C}$ ratio of 0.7 ) obtained with the semi-empirical method described in Berkemeier et $a l^{42}$ (orange shadings). The values determined for $D_{\mathrm{b}, \mathrm{O}_{3}}$ are slightly shifted towards lower diffusivities compared to recent experimental data of less oxidised $\alpha$-pinene SOA in ref. 54 (green shadings) and ref. 72 (purple shadings), but show the same qualitative shape. The difference is in line with the results of Berkemeier et al. ${ }^{42}$ who predicted a decrease in diffusion rates upon chemical ageing, i.e. by an increase in molecular $\mathrm{O} / \mathrm{C}$ ratio. At a molecular $\mathrm{O} / \mathrm{C}$ ratio of 0.5 , the estimated diffusion coefficients of Berkemeier et al. ${ }^{42}$ coincide with the results of Lienhard et al. ${ }^{54}$ who determined the molecular O/C ratio of their SOA samples to 0.53. A part of the difference between $D_{\mathrm{b}, \mathrm{H}_{2} \mathrm{O}}$ and $D_{\mathrm{b}, \mathrm{O}_{3}}$ can be attributed to the molecular size of ozone, which is almost three times larger than water.

Hence, results are closely related, even though the method of determining diffusion coefficients in this paper is conceptually

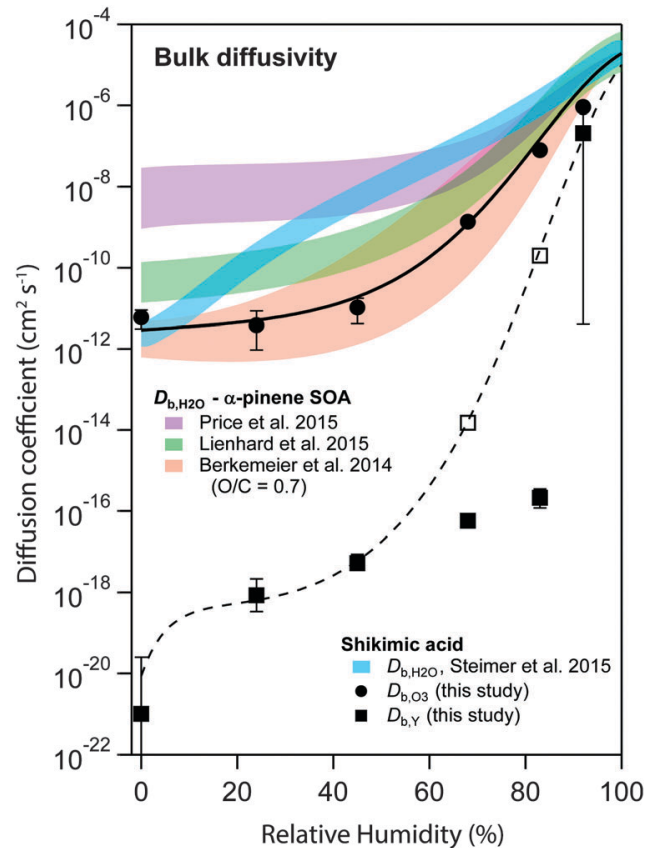

Fig. 6 Humidity dependence of the bulk diffusion coefficients of ozone $\left(D_{\mathrm{b}, \mathrm{O}_{3}}\right.$, black circles) and shikimic acid $\left(D_{\mathrm{b}, \mathrm{Y}}\right.$, black squares) as determined by global optimization to the experimental data set. The black solid and the dashed line represent a fit to a Vignes-type equation for ozone and shikimic acid, respectively. Open square markers indicate model runs including product effects, consistent with the Vignes-type fit. Blue shadings are measurements of water diffusivity in shikimic acid as measured by Steimer et al. ${ }^{59}$ Red shadings indicate an estimate of water diffusivity in SOA corresponding to the molecular O/C ratio of shikimic acid. ${ }^{42}$ Measurements on SOA at slightly lower molecular $\mathrm{O} / \mathrm{C}$ ratio have been performed by Price et al. (purple shadings) and Lienhard et al. (green shadings). ${ }^{54,72}$

very different to the established methods for determination of water diffusion coefficients in organic material. In previous work using a steady-state approach, it was not possible to reconcile diffusion coefficients from RH-dependent kinetic data. ${ }^{53}$

The $D_{\mathrm{b}, \mathrm{O}_{3}}$ curve can be fitted as a function of molar organic fraction $x_{\text {org }}$ by the Vignes-type eqn (6) used in Lienhard et al. ${ }^{54}$

$$
\begin{gathered}
D_{\mathrm{b}}=\left(D_{\mathrm{b}}^{\mathrm{W}}\right)^{\alpha\left(1-x_{\mathrm{org}}\right)}\left(D_{\mathrm{b}}^{\mathrm{org}}\right)^{\alpha x_{\mathrm{org}}} \\
\ln \alpha=x_{\text {org }}^{2}\left(C+3 D-4 D x_{\text {org }}\right)
\end{gathered}
$$

$D_{\mathrm{b}, \mathrm{O}_{3}}^{\mathrm{w}}$ and $D_{\mathrm{b}, \mathrm{O}_{3}}^{\mathrm{org}}$ are the ozone diffusivity in pure water and pure organics, respectively. The equation uses a correction factor $\alpha$ that has the form of an activity coefficient. The parameters for eqn (6) and (7) used in this study are listed in Table S3 (ESI $\dagger$ ).

Fig. 6 also includes the humidity dependence of $D_{\mathrm{b}, \mathrm{Y}}$, which shows many orders of magnitude lower values than $D_{\mathrm{b}, \mathrm{O}_{3}}$. $D_{\mathrm{b}, \mathrm{Y}}$ increases from $\sim 10^{-20} \mathrm{~cm}^{2} \mathrm{~s}^{-1}$ to $10^{-7} \mathrm{~cm}^{2} \mathrm{~s}^{-1}$ upon increase of RH, reflecting that the phase state of shikimic acid changes from amorphous solid over semi-solid to liquid (moistureinduced phase transformation ${ }^{73}$ ), compliant with earlier work. ${ }^{39}$ The dashed black line represents a fit using the Vignes-type equation. Note that a good fit was only obtained neglecting the values at 68 and $83 \% \mathrm{RH}$. At this intermediate humidity, $D_{\mathrm{b}, \mathrm{Y}}$ needs to be $\sim 10^{-17} \mathrm{~cm}^{2} \mathrm{~s}^{-1}$ to explain the slow reduction in $\gamma$ at 
long reaction times seen in the experimental data ( $c f$. Fig. 1) as $D_{\mathrm{b}, \mathrm{Y}}$ controls the slope of this reduction ( $c f$. Fig. S1, ESI $\dagger$ ). Such low diffusivity would lead to incomplete mixing of bulk material in the model (as discussed in Fig. 5 and Section 3.2), which is not in line with previous results by Steimer et al. ${ }^{69}$ who observed well-mixed particles during ozonolysis down to $67 \% \mathrm{RH}$ using STXM microscopy. This disparity may be caused by product effects not captured by the kinetic model: A slight decrease in $D_{\mathrm{b}, \mathrm{O}_{3}}$ or $H_{\mathrm{cp}, \mathrm{O}_{3}}$ over time could lead to a similar deceleration of reaction kinetics. A recent study has shown that oxidative processing of organic aerosols can lead to an increase of viscosity, and hence decrease of bulk diffusivity according to the StokesEinstein relation. ${ }^{23}$ Also, polar products could preferentially adsorb to the surface, blocking surface sites and reducing surface-bulk transport rates. Such product effects reducing diffusivities cannot be distinguished in the model from incomplete transport of shikimic acid to the surface. Test runs with composition-dependent $D_{\mathrm{b}, \mathrm{O}_{3}}$ showed that the values of $D_{\mathrm{b}, \mathrm{Y}}$ indicated by the open square markers in Fig. 6 could be supported by the model if $D_{\mathrm{b}, \mathrm{O}_{3}}$ would decrease over the course of the $16 \mathrm{~h}$ experiment by factors of 5 and 2.5 at $68 \% \mathrm{RH}$ and $83 \% \mathrm{RH}$, respectively. In this scenario, no diffusion gradients would be present in shikimic acid at $68 \%$ and $83 \%$ RH (Fig. S2, ESI $\dagger)$, which is in contrast to the results shown in Fig. 6, but consistent with STXM experiments. ${ }^{53}$ A thorough discussion of the effect of reaction products on reactive uptake is however beyond the scope of this study as laboratory experiments only measured gas-phase ozone concentrations. The very low values for $D_{\mathrm{b}, \mathrm{Y}}$ obtained in this study at medium to high $\mathrm{RH}$ values should hence be handled with reservation.

Fig. 7 shows the humidity dependence of the Henry's law coefficient of ozone, $H_{\mathrm{cp}, \mathrm{O}_{3}}$, which is used to describe the saturation concentration of ozone in the organic matrix. Henry's law coefficients (green diamonds) were found to decrease with decreasing organic weight fraction, $w_{\text {org }}$, following a logarithmic mixing rule (green solid line), eqn (8). $H_{\mathrm{cp}, \mathrm{O}_{3}}^{\mathrm{w}}$ and $H_{\mathrm{cp}, \mathrm{O}_{3}}^{\mathrm{org}}$ are the Henry's law coefficients of ozone in pure water ${ }^{74}$ and pure organics, respectively.

$$
H_{\mathrm{cp}, \mathrm{O}_{3}}=\exp \left(\left(1-w_{\mathrm{org}}\right) \log \left(H_{\mathrm{cp}, \mathrm{O}_{3}}^{\mathrm{w}}\right)+w_{\mathrm{org}} \log \left(H_{\mathrm{cp}, \mathrm{O}_{3}}^{\mathrm{org}}\right)\right)
$$

The value of $1.8 \times 10^{-4} \mathrm{~mol} \mathrm{~cm}^{-3} \mathrm{~atm}^{-1}$ determined for $H_{\mathrm{cp}, \mathrm{O}_{3}}^{\mathrm{org}}$ seems reasonable compared to Henrys law coefficients for decane $\mathrm{e}^{75}$ and oleic acid ${ }^{67}$ (dashed black lines in Fig. 7).

The organic acid thus shows an effect similar to the salting-out behaviour known for inorganic solutes, but acts in the opposite direction ("salting-in") comparable to other organic solvents investigated previously such as acetic acid. ${ }^{76}$ Error bars in Fig. 6 and 7 represent the interval in which a model parameter can be varied until the total residual $R$ increases by $20 \%$.

Note that these 1-dimensional degrees of freedom are measures of parameter sensitivity and do not consider interactions between model parameters, which will be discussed in Section 3.4. The optimization yielded a bulk reaction rate coefficient $k_{\mathrm{BR}}$ of $4.4 \times 10^{-18} \mathrm{~cm}^{3} \mathrm{~s}^{-1}$, which compares well to literature values for similarly functionalised molecules such as maleic acid

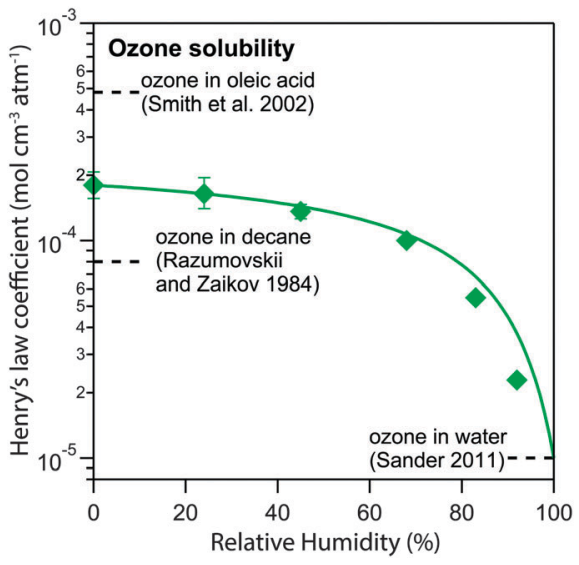

Fig. 7 Henry's law coefficient of ozone $H_{\mathrm{cp}, \mathrm{O}_{3}}$ (green diamonds) determined by global optimization to the experimental data set. The data can be explained with a logarithmic mixing rule (green solid line).

$\left(1.7 \times 10^{-18} \mathrm{~cm}^{3} \mathrm{~s}^{-1}\right)$ or fumaric acid $\left(1.0 \times 10^{-17} \mathrm{~cm}^{3} \mathrm{~s}^{-1}\right)$ in aqueous solution. ${ }^{77}$ The value is also consistent with the bulk reaction rate coefficient of $6.1 \times 10^{-18} \mathrm{~cm}^{3} \mathrm{~s}^{-1}$ obtained by steady-state analysis. ${ }^{53}$

The surface reaction rate coefficient for ozonolysis of shikimic acid $k_{\text {SLR1 }}\left(8.5 \times 10^{-16} \mathrm{~cm}^{2} \mathrm{~s}^{-1}\right)$ is found to be one order of magnitude higher than the ozone self-reaction rate coefficient $k_{\text {SLR2 }}\left(4.3 \times 10^{-17} \mathrm{~cm}^{2} \mathrm{~s}^{-1}\right)$. A self-reaction of ozone at the particle surface could not be captured by steady-state analysis using the resistor model approach, leading to overall lower correlation to the experimental data especially at dry $\mathrm{RH}$, or an overestimation of bulk diffusion coefficients at low RH. ${ }^{53}$ Including such a selfreaction adds a constant loss term that enables to describe the experimental data at dry $\mathrm{RH}$ while staying consistent with data obtained using other experimental techniques. ${ }^{59,69}$

The bulk-surface partitioning parameter $K_{\mathrm{bs}}$ also shows humidity-dependence and ranges from $2.0-9.3 \times 10^{-9} \mathrm{~cm}$, indicating that the relative amount of molecules accessible by surface adsorbed reactants increases with humidity. This suggests that shikimic acid molecules are slightly surface active and enrich at the surface of more dilute aqueous solutions. Note that while $K_{\mathrm{bs}}$ spans almost one order of magnitude, the surface concentration increases only by $84 \%$ over the entire humidity range due to overall dilution of the aqueous solution. The moderate increase could be due to a packing effect: at low $\mathrm{RH}$, molecules might show a random orientation toward the particle surface, while at high $\mathrm{RH}$ molecules may form a structured outer layer on top of the aqueous solution. In addition, the mobility of the surface monolayer could play a significant role: at low $\mathrm{RH}$, surface molecules may be immobile and a reactive site that is directed away from the surface would be inaccessible by adsorbed reactants. Such a molecule would not be able to undergo surface layer reaction, which effectively reduces the surface concentration of reaction sites irrespective of the concentration of surface molecules. These findings are supported by Vieceli et al. ${ }^{58}$ who demonstrated the importance of molecular orientation and double bond orientation in alkene ozonolysis systems at different phase states using molecular dynamics simulations. 
A different interpretation of this enhanced surface reactivity could be influence of water molecules on the chemical reaction as has been observed in the ozonolysis of maleic acid ${ }^{78}$ and phosphocholine. ${ }^{79}$ This would however require existence of a longlived reaction intermediate whose decomposition can be induced with water molecules and serves as rate-determining step in the reaction mechanism. We discuss the possibility of such reaction intermediates in Section 3.5.

Analysis of the rate coefficients for surface-bulk exchange $k_{\mathrm{b}, \mathrm{s}, \mathrm{O}_{3}}$ and $k_{\mathrm{ss}, \mathrm{b}, \mathrm{Y}}$ reveals that the exchange process cannot be described simply by means of diffusion. The surface-bulk exchange rates are accelerated compared to the rates of bulk diffusion layer at low $\mathrm{RH}$ and are found to be overall less dependent on RH. Such surface layers of enhanced mobility are well-known in quasi-liquid surface layers of solid surfaces. ${ }^{60}$ At low RH, the surface-bulk-exchange rates had thus little influence on calculation results. At higher $\mathrm{RH}, k_{\mathrm{b}, \mathrm{s}, \mathrm{O}_{3}}$ approaches the value expected for a pure diffusive process, whereas $k_{\mathrm{ss}, \mathrm{b}, \mathrm{Y}}$ behaves differently: surface-bulk exchange is slowed down heavily at $92 \% \mathrm{RH}$ compared to the analogous diffusion process. Hence, replenishment of bulk molecules on the surface is at low $\mathrm{RH}$ limited by bulk transport and at high $\mathrm{RH}$ limited by bulk-surface exchange. A possible reason is the replacement of shikimic acid molecules at the surface by more polar products, preventing an effective surface reaction after depletion of the initial surface layer. Such a low surface-bulk exchange rate was necessary to describe the experimental data, as otherwise the surface reaction plateau, clearly visible in the experimental data, was not reproduced by the model.

\subsection{Uniqueness of the kinetic parameter set}

Even though a kinetic parameter set was found to fit an experimental data set sufficiently well, these parameters might not constitute the only set generating the same model output and hence not be a unique solution of the optimization problem. If a subset of parameters is mutually dependent, different combinations of these parameters will give an identical result. It is then not guaranteed that a fitted parameter value equals its physical counterpart. In the following we will refer to such parameter pairs or sets as non-orthogonal parameters. We show that the problem of non-orthogonality can often be overcome by fitting many data sets obtained at various experimental conditions and over long time spans. Two parameters might only differ in their influence on the calculation result at specific points during the reaction course (Fig. S1 and S3, ESI $\dagger$ ) or show a different effect on the model output under varying experimental conditions.

The existence of non-orthogonal parameter sets was investigated for many combinations of input parameters by distributing the parameters on two axes and calculating the total residual $R$ as a $2 \mathrm{D}$ contour map. Parameters $\lambda_{i}$ were varied by a factor $f\left(\lambda_{i}\right)$ yielding $\lambda_{i}^{\prime}=f\left(\lambda_{i}\right) \lambda_{i}$ with $f\left(\lambda_{i}\right)$ spanning four orders of magnitude from 0.01 to 100 . Parameters on the same axis were varied uniformly. A few selected results computed at $24 \% \mathrm{RH}$ are shown as contour plots in Fig. 8. By far the most common result of this analysis was a distinct minimum in which also the global fitting result (red cross) fell. An example for this is Fig. 8A, which shows a $2 \mathrm{D}$ contour map for the parameters $\tau_{\mathrm{d}, \mathrm{O}_{3}}$ and $\sigma_{\mathrm{O}_{3}}$. While both parameters control the Langmuir adsorption equilibrium concentration of ozone at the surface and are thus potentially nonorthogonal, a distinct minimum was found. The two parameters decouple as experimental data with multiple ozone gas phase concentrations is used and $\tau_{\mathrm{d}, \mathrm{O}_{3}}$ and $\sigma_{\mathrm{O}_{3}}$ behave differently upon change in $\left[\mathrm{O}_{3}\right]_{\mathrm{g}}$.

Non-orthogonality was observed when $k_{\mathrm{BR}}, k_{\mathrm{b}, \mathrm{s}, \mathrm{O}_{3}}$ and $D_{\mathrm{b}, \mathrm{O}_{3}}$ were varied uniformly and plotted against $H_{\mathrm{cp}, \mathrm{O}_{3}}$ in Fig. 8B. This finding shows that the values of the parameters $H_{\mathrm{cp}, \mathrm{O}_{3}}, k_{\mathrm{BR}}$, $k_{\mathrm{b}, \mathrm{s}, \mathrm{O}_{3}}$ and $D_{\mathrm{b}, \mathrm{O}_{3}}$ cannot be uniquely determined unless any of the parameters is constrained. Note that only the simultaneous increase of the diffusion and reaction parameters can compensate the increase in $\mathrm{H}_{\mathrm{cp}, \mathrm{O}_{3}}$, for smaller subsets of the parameters full non-orthogonality was not observed (Fig. 8C). Hence, constraining one of these parameters would determine all others. Since the Henry's law coefficient of ozone can be constrained fairly well in the aqueous solution, the $92 \% \mathrm{RH}$ data set can be used to constrain all other parameters. By assuming a $H_{\mathrm{cp}, \mathrm{O}_{3}}$ between $1-3 \times 10^{-5} \mathrm{~mol} \mathrm{~cm}^{-3} \mathrm{~atm}^{-1}, k_{\mathrm{BR}}$ can be constrained between $3 \times 10^{-18}$ and $1 \times 10^{-17} \mathrm{~cm}^{2} \mathrm{~s}^{-1}, D_{\mathrm{b}, \mathrm{O}_{3}}$ between $2-6 \times 10^{-6} \mathrm{~cm}^{2} \mathrm{~s}^{-1}$ and $k_{\mathrm{b}, \mathrm{s}, \mathrm{O}_{3}}$ between $14.5-43.5 \mathrm{~cm} \mathrm{~s}^{-1}$. The diffusion coefficients $D_{\mathrm{b}, \mathrm{O}_{3}}$ and $D_{\mathrm{b}, \mathrm{Y}}$ were also found to be orthogonal (Fig. $8 \mathrm{D}$ ). Note that with a larger subset of parameters, the chance of finding
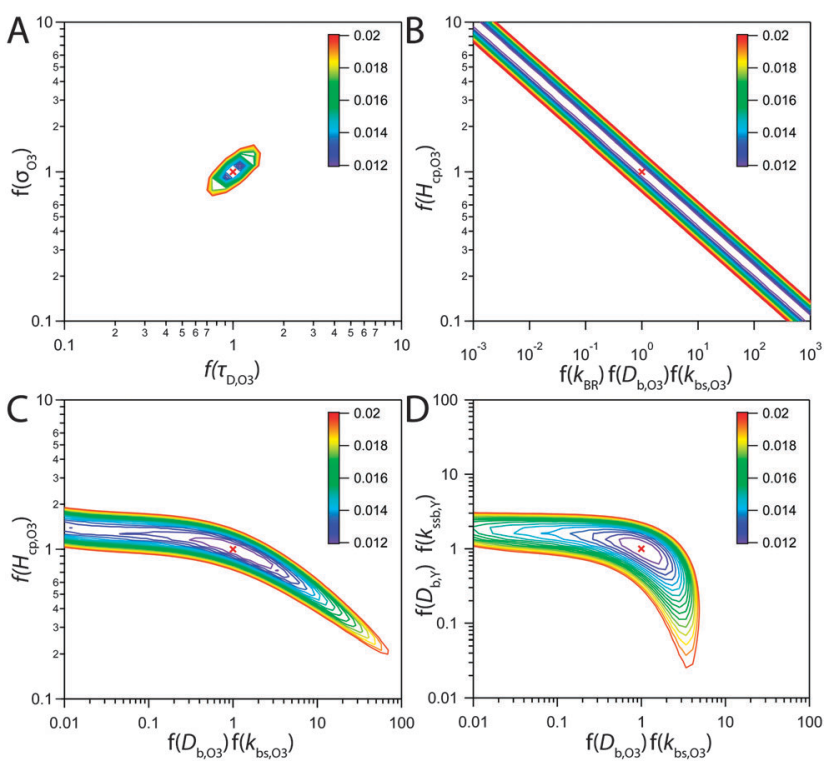

Fig. 8 Total residual $R$ (colour bar) between experimental data and KM-SUB model results in the local environment of the best fitting parameter set (red crosses, cf. Table S2, ESI $\dagger$ ). The best fit parameters $\lambda_{i}$ were multiplied by a factor $f\left(\lambda_{j}\right)$ and the residual calculated after eqn (5) and $R=\sum r_{i}$, to obtain the depicted contour lines. Panel A shows a distinct minimum in $R$, indicating that an optimum value for both $\sigma_{\mathrm{O}_{3}}$ and $\tau_{\mathrm{d}, \mathrm{O}_{3}}$ was found in the 2D subspace. Panel B shows that when $k_{\mathrm{BR}}, D_{\mathrm{b}, \mathrm{O}_{3}}$ and $k_{\mathrm{b}, \mathrm{s}, \mathrm{O}_{3}}$ are varied uniformly against $H_{\mathrm{cp}, \mathrm{O}_{3}}$ a stretched out unconfined minimum is obtained and the parameters are thus non-orthogonal and hence not uniquely defined. Panel $C$ showcases that the same dependence is not observed for subsets of these parameters. Panel $D$ shows that diffusivities of $\mathrm{O}_{3}$ and shikimic acid are not interchangeable. 
non-orthogonal input parameters can be higher. We tested up to four parameters in two dimensions, as this was the maximum computationally feasible. We cannot exclude that more flexibility exists in the choice of kinetic input parameters reproducing the experimental data.

Another way of detecting dependencies between input parameters $\lambda_{i}$ is to use sensitivity coefficients $S\left(\lambda_{i}\right)$. Once sensitivity coefficients are obtained this technique is computationally much more efficient as no further model evaluations are needed. A short description of normalised sensitivity coefficients and the method is given in the supplement (Section B). However, no additional co-dependence of parameters was detected using this method.

\subsection{ROI reaction mechanism}

The desorption lifetime of ozone and the effective molecular cross section of physisorbed ozone are not compliant with a pure physical adsorption process of ozone. In the following we will suggest an alternative reaction mechanism including the formation of reactive oxygen intermediates (ROI) to explain this behaviour.

The desorption lifetime of ozone, $\tau_{\mathrm{d}, \mathrm{O}_{3}}$, was determined to be $5.3 \times 10^{-4} \mathrm{~s}$, which is many orders of magnitude larger than the values of order nanoseconds estimated by molecular dynamics simulations ${ }^{63}$ and density functional theory. ${ }^{80}$ Thus, this value must be an effective value that represents additional processes such as decomposition of ozone and formation of long-lived reactive oxygen intermediates (ROI). ${ }^{62,81}$ A physisorption process with unusually long desorption lifetime also leads to artefacts in the simulation data at the sub-minute time scale: a long residence time leads to high initial uptake of ozone onto the organic film, causing the flow tube to deplete on ozone. The experimental data however shows no evidence for full depletion of ozone in the early stages of the experiment, ${ }^{53}$ which can only be realised in the kinetic model using desorption lifetimes in the sub-microsecond time range.

The effective molecular cross section of physisorbed ozone, $\sigma_{\mathrm{O}_{3}}$, is found to be $2.4 \times 10^{-14} \mathrm{~cm}^{2}$, which is higher than the geometrical value of $1.5 \times 10^{-15} \mathrm{~cm}^{2}$, hence effectively reducing the number of sorption sites for ozone. As discussed in Section 2.1 this might be due to electrostatic repulsion of adsorbed molecules or dictated by surface morphology, i.e. ozone molecules adsorbing only to certain structural features of the surface. The corresponding maximum surface concentration of adsorbed ozone of $2.4 \times 10^{13} \mathrm{~cm}^{-2}$ closely resembles the coverage of surface-accessible double bonds of 1-2 $\times$ $10^{13} \mathrm{~cm}^{-2}$ expected from the surface cross section of shikimic acid $\sigma_{\mathrm{Y}}$, suggesting that surface-adsorbed molecules may interact with the double bond of shikimic acid and pointing towards formation of ROI on the surface.

Formation of ROI on the surface as a form of ozone chemisorption can also explain the emergence of an additional plateau in the experimental data at very low values of $\gamma$ : while $\mathrm{O}_{3}$ molecules are unlikely to react with another directly by simple collision, decomposition into ROI and subsequent recombination of two chemisorbed $\mathrm{O}_{3}$ molecules could effectively lead to self-reaction of $\mathrm{O}_{3}$ and explain the non-zero uptake of $\mathrm{O}_{3}$ onto dry shikimic acid at long reaction times (Fig. 1).

The accepted mechanism of alkene ozonolysis in both, gas and condensed phases, involves formation of a trioxyl diradical (primary ozonide, PO), following the Criegee mechanism. ${ }^{82-84}$ The PO further decomposes to a Criegee intermediate and a carbonyl compound. ${ }^{82}$ The following chemical mechanism (R1-R3) was used to draw a simplified picture of this rather complicated surface chemistry. Subscripts s and ss denote species adsorbed in the sorption layer or surface-exposed in the quasi-static surface layer, respectively. For ozone from the sorption layer we assume a desorption lifetime of $3.2 \times 10^{-9} \mathrm{~s}$, corresponding to a physisorption energy of $20 \mathrm{~kJ} \mathrm{~mol}^{-1} \cdot{ }^{62}$

$$
\begin{gathered}
\mathrm{O}_{3}(\mathrm{~s})+\mathrm{Y}(\mathrm{ss}) \rightarrow \mathrm{ROI}-1(\mathrm{ss}) \\
\mathrm{ROI}-1(\mathrm{ss}) \rightarrow \mathrm{O}_{3}(\mathrm{~s})+\mathrm{Y}(\mathrm{ss}) \\
\mathrm{ROI}-1(\mathrm{ss}) \rightarrow \text { product }
\end{gathered}
$$

The reaction rate coefficients $k_{\mathrm{R} 1}$ to $k_{\mathrm{R} 3}$ were optimised using the MCGA algorithm. $k_{\mathrm{R} 1}$ was found to be $1 \times 10^{-10} \mathrm{~cm}^{2} \mathrm{~s}^{-1}$, corresponding to an activation energy of $42 \mathrm{~kJ} \mathrm{~mol}^{-1}$. The back reaction to ozone (R2) was tested, but found to be too slow to influence calculation results, suggesting a relatively stable compound such as PO as intermediate.

Quantum mechanical calculations suggest an activation barrier of $\sim 60 \mathrm{~kJ} \mathrm{~mol}^{-1}$ for the reaction of PO to Criegee intermediates. ${ }^{86-88}$ Our model results agree well with these calculations and the corresponding energy profile is shown in Fig. 9. ${ }^{62}$

Note that since no experimental data for decay of the bulk material $\mathrm{Y}$ was available, $k_{\mathrm{R} 2}$ and $k_{\mathrm{R} 3}$ and the corresponding activation energies could not be uniquely constrained, and hence the identity of the reactive intermediate not unerringly identified. In an alternative formulation of this mechanism, a reversible $\pi$-complex between ozone and the double bond could also function as reactive intermediate. ${ }^{83,84}$

While reconciling ozone adsorption properties, the above mechanism cannot fully describe the stable long-term uptake of ozone observed in the experiments under dry conditions since shikimic acid is depleted at the surface under these conditions, hampering the formation of ROI (Fig. S4, ESI $\dagger$ ).

Ozone decomposition is known to occur on aromatic surfaces ${ }^{62}$ and even on inert surfaces such as mineral dust, ${ }^{88}$ demanding an alternative pathway for ozone chemisorption. We thus tested a mechanism involving a second ROI, which can be thought of as oxygen adatom, whose formation is independent of double bond concentration. Formation and consumption of $\mathrm{O}_{2}$ was neglected in these calculations as its concentration can be assumed constant.

$$
\begin{gathered}
\mathrm{O}_{3}(\mathrm{~s}) \rightarrow \mathrm{ROI}-2(\mathrm{~s})+\mathrm{O}_{2}(\mathrm{~s}) \\
\mathrm{ROI}-2(\mathrm{~s})+\mathrm{O}_{2}(\mathrm{~s}) \rightarrow \mathrm{O}_{3}(\mathrm{~s}) \\
\mathrm{ROI}-2(\mathrm{~s})+\mathrm{Y}(\mathrm{ss}) \rightarrow \text { product } \\
\mathrm{ROI}-2(\mathrm{~s})+\mathrm{ROI}-2(\mathrm{~s}) \rightarrow \mathrm{O}_{2}(\mathrm{~s})
\end{gathered}
$$




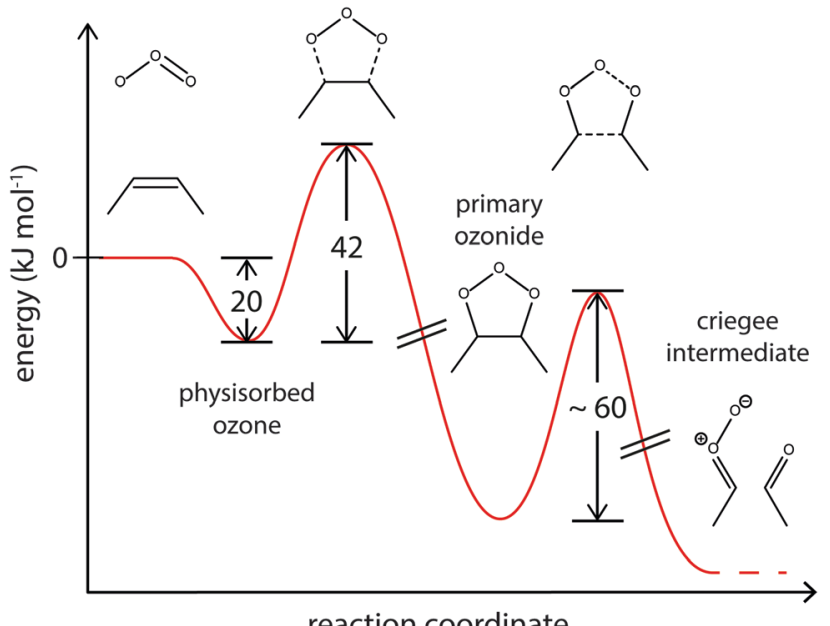

reaction coordinate

Fig. 9 Suggested energy profile for the surface reaction of shikimic acid with ozone, following a Criegee-type mechanism. The model parameters obtained with global optimization give activation energies of $20 \mathrm{~kJ} \mathrm{~mol}^{-1}$ for desorption of physisorbed oxygen and $42 \mathrm{~kJ} \mathrm{~mol}^{-1}$ for formation of the reactive oxygen intermediate. This intermediate reacts to Criegee intermediates and carbonyl compounds. ${ }^{85-87}$

$k_{\mathrm{R} 4}$ reveals a fast first-order decomposition of physisorbed ozone at a rate of $7.9 \times 10^{4} \mathrm{~s}^{-1}$, corresponding to an activation energy of $40 \mathrm{~kJ} \mathrm{~mol}^{-1} . k_{\mathrm{R} 6}$ and $k_{\mathrm{R} 7}$ were determined to $2.5 \times 10^{-14}$ and $3.1 \times 10^{-14} \mathrm{~cm}^{2} \mathrm{~s}^{-1}$, respectively. The back reaction to ozone (R5) was treated as pseudo-first order reaction and found not to influence ozone loss. Using this mechanism, the self-reaction plateau in the reactive uptake coefficient $\gamma$ could be reproduced in the kinetic model (Fig. S5, ESI $\dagger$ ). Note that the combination of reactions (R4) and (R7) can be regarded as a catalytic cycle of ozone destruction $\left(2 \mathrm{O}_{3} \rightarrow 3 \mathrm{O}_{2}\right)$. The initial reactions of ozone chemisorption and decomposition (R1, R4) exhibit very similar activation energies and also correlate well with previous results on aromatic surfaces, ${ }^{62}$ supporting that heterogeneous ozone uptake may exhibit a similar reaction profile on various surfaces. ${ }^{89}$ The necessity of two ROIs in the kinetic model to reconcile measurement data indicates that multiple different types of ROI may coexist.

\section{Summary and outlook}

Multiphase chemistry of ozone plays an important role in degradation and chemical transformation of atmospheric marker substances. The phase state of organic aerosols is expected to vary as a function of environmental conditions such as temperature and relative humidity. Shikimic acid appears to be a good model compound for organic aerosol, as it similarly adopts a (semi)-solid to liquid phase state depending on $\mathrm{RH}$. We demonstrate that phase state strongly affects the rate of reactive uptake and chemical ageing of organic aerosols. The KM-SUB analysis shows that the predominant kinetic regimes change as a function of time and relative humidity and reveals that even the quasistationary states along the reaction coordinate cannot be properly described with resistor or simple kinetic models, i.e. without the use of depth-resolved computation. Even though depth-resolved computation may be too expensive for large-scale atmospheric models, KM-SUB can be used to develop simple but robust parameterizations for atmospheric models.

The model simulations suggest the formation of reactive oxygen intermediates, likely primary ozonides or $\mathrm{O}$ atoms, at the particle surface. Such intermediates can explain the low sorption site density and the long effective desorption lifetime of ozone needed in Langmuir-Hinshelwood type descriptions of this system. The ROIs provide potential pathways for the self-reaction and catalytic destruction of ozone needed to explain the long-term uptake observed under dry conditions.

The ROI-related pathways of ozone degradation at the surface, together with the amorphous solid phase state of organic matter under cold and dry conditions, may help to explain how reactive organic compounds in the bulk of atmospheric aerosol particles are effectively shielded from degradation by ozone. The apparent abundance and longevity of ROIs has implications for human health as they can generate cytotoxic free radicals and cause oxidative stress upon inhalation of particulates. ${ }^{90}$

For future experimental studies, the effect of temperature on reactive gas uptake would be of major interest as temperature affects not only the particle phase state, but also the rates of chemical reactions. Simultaneous detection of both oxidant uptake and decay of bulk material would further constrain the kinetic parameter set. We suggest the use of kinetic flux models alongside future laboratory experiments to detect kinetic regimes and push the reaction system into various cases of well-understood kinetic behaviour through choice of experimental conditions. Large data sets under wide experimental conditions would help to constrain the optimization parameter space and to identify processes necessary for accurate description of the kinetic data. Additional measurements of experimentally accessible physical parameters such as Henry's law and diffusion coefficients as function of humidity and temperature would hereby strongly facilitate the global optimization of models to large experimental data sets. Experiments (or simulations) on the sub-second time scale might help to shine further light on surface adsorption processes. To reveal details about the chemical reaction mechanism, spectroscopic techniques sensitive to short-lived and radical species need to be applied in conjunction with further kinetic experiments and modelling studies to identify the important intermediate species and their interactions.

\section{Acknowledgements}

This work was funded by the Max Planck Society (MPG) and the EU project PEGASOS. T. B. was supported by the Max Planck Graduate Center with the Johannes Gutenberg-Universität Mainz (MPGC). M. Ammann acknowledges support by the Swiss National Science Foundation (grant no. 163074). We would like to thank Andrew J. Huisman, Claudia Marcolli, Daniel M. Lienhard, Peter Spichtinger, Andrea Pozzer and Rolf Sander for helpful discussions. 


\section{Notes and references}

1 M. Kanakidou, et al., Atmos. Chem. Phys., 2005, 5, 1053-1123. 2 M. Hallquist, et al., Atmos. Chem. Phys., 2009, 9, 5155-5235. 3 J. L. Jimenez, et al., Science, 2009, 326, 1525-1529.

4 M. O. Andreae and D. Rosenfeld, Earth-Sci. Rev., 2008, 89, 13-41.

5 U. Pöschl, Angew. Chem., Int. Ed., 2005, 44, 7520-7540.

6 U. Pöschl and M. Shiraiwa, Chem. Rev., 2015, 115, 4440-4475.

7 P. J. Ziemann and R. Atkinson, Chem. Soc. Rev., 2012, 41, 6582-6605.

8 M. Shiraiwa, et al., Proc. Natl. Acad. Sci. U. S. A., 2011, 108, 11003-11008.

9 S. Zhou, et al., Faraday Discuss., 2013, 165, 391-406.

10 M. Kuwata and S. T. Martin, Proc. Natl. Acad. Sci. U. S. A., 2012, 109, 17354-17359.

11 J. H. Slade and D. A. Knopf, Geophys. Res. Lett., 2014, 41, 5297-5306.

12 A. M. Arangio, et al., J. Phys. Chem. A, 2015, 119, 4533-4544. 13 J. H. Kroll, et al., J. Phys. Chem. A, 2015, 119, 10767-10783.

14 I. J. George and J. P. D. Abbatt, Nat. Chem., 2010, 2, 713-722.

15 M. Shiraiwa, U. Pöschl and D. A. Knopf, Environ. Sci. Technol., 2012, 46, 6630-6636.

16 Y. Rudich, N. M. Donahue and T. F. Mentel, Annu. Rev. Phys. Chem., 2007, 58, 321-352.

17 M. R. Alfarra, et al., Atmos. Chem. Phys., 2012, 12, 6417-6436.

18 B. Wang, et al., J. Phys. Chem. A, 2015, 119, 4498-4508.

19 M. Shiraiwa, et al., Proc. Natl. Acad. Sci. U. S. A., 2013, 110, 11746-11750.

20 Y. Rudich, Chem. Rev., 2003, 103, 5097-5124.

21 F. D. Pope, et al., Environ. Sci. Technol., 2010, 44, 6656-6660.

22 A. T. Lambe, et al., Atmos. Chem. Phys., 2011, 11, 8913-8928.

23 N. A. Hosny, et al., Chem. Sci., 2016, 7, 1357-1367.

24 T. D. Vaden, et al., Proc. Natl. Acad. Sci. U. S. A., 2011, 108, 2190-2195.

25 J. P. D. Abbatt, A. K. Y. Lee and J. A. Thornton, Chem. Soc. Rev., 2012, 41, 6555-6581.

26 M. Shiraiwa, et al., Phys. Chem. Chem. Phys., 2013, 15, 11441-11453.

27 J. Laskin, et al., Anal. Chem., 2010, 82, 2048-2058.

28 R. D. McWhinney, et al., Environ. Sci. Technol., 2011, 45, 2131-2136.

29 C. Pfrang, M. Shiraiwa and U. Pöschl, Atmos. Chem. Phys., 2011, 11, 7343-7354.

30 D. A. Knopf, L. M. Anthony and A. K. Bertram, J. Phys. Chem. A, 2005, 109, 5579-5589.

31 C. Kidd, et al., Proc. Natl. Acad. Sci. U. S. A., 2014, 111, 7552-7557.

32 F. H. Marshall, et al., Chem. Sci., 2016, 7, 1298-1308.

33 B. Zobrist, et al., Atmos. Chem. Phys., 2008, 8, 5221-5244.

34 B. J. Murray, et al., Nat. Geosci., 2010, 3, 233-237.

35 A. Virtanen, et al., Nature, 2010, 467, 824-827.

36 T. Koop, et al., Phys. Chem. Chem. Phys., 2011, 13, 19238-19255.

37 E. Saukko, et al., Atmos. Chem. Phys., 2012, 12, 7517-7529.

38 R. M. Power, et al., Chem. Sci., 2013, 4, 2597-2604.
39 L. Renbaum-Wolff, et al., Proc. Natl. Acad. Sci. U. S. A., 2013, 110, 8014-8019.

40 E. Abramson, et al., Phys. Chem. Chem. Phys., 2013, 15, 2983-2991.

41 H. J. Tong, et al., Atmos. Chem. Phys., 2011, 11, 4739-4754.

42 T. Berkemeier, et al., Atmos. Chem. Phys., 2014, 14, 12513-12531.

43 H. C. Price, et al., Atmos. Chem. Phys., 2014, 14, 3817-3830. 44 J. F. Davies and K. R. Wilson, Chem. Sci., 2015, 6, 7020-7027. 45 B. J. Finlayson-Pitts and J. N. Pitts, Chemistry of the upper and lower atmosphere, Academic Press, San Diego, California, 1999. 46 D. R. Worsnop, et al., Geophys. Res. Lett., 2002, 29, 57.

47 T. Berkemeier, et al., Atmos. Chem. Phys., 2013, 13, 6663-6686.

48 G. D. Smith, et al., J. Phys. Chem. A, 2003, 107, 9582-9587.

49 M. Shiraiwa, C. Pfrang and U. Pöschl, Atmos. Chem. Phys., 2010, 10, 3673-3691.

50 M. Shiraiwa, et al., Atmos. Chem. Phys., 2012, 12, 2777-2794. 51 P. Roldin, et al., Atmos. Chem. Phys., 2014, 14, 7953-7993.

52 C. Pfrang, M. Shiraiwa and U. Pöschl, Atmos. Chem. Phys., 2010, 10, 4537-4557.

53 S. S. Steimer, et al., Phys. Chem. Chem. Phys., 2015, 17, 31101-31109.

54 D. M. Lienhard, et al., Atmos. Chem. Phys., 2015, 15, 13599-13613.

55 U. Pöschl, Y. Rudich and M. Ammann, Atmos. Chem. Phys., 2007, 7, 5989-6023.

56 D. A. Knopf, U. Pöschl and M. Shiraiwa, Anal. Chem., 2015, 87, 3746-3754.

57 B. Zobrist, et al., Phys. Chem. Chem. Phys., 2011, 13, 3514-3526.

58 J. Vieceli, O. L. Ma and D. J. Tobias, J. Phys. Chem. A, 2004, 108, 5806-5814.

59 S. S. Steimer, et al., Atmos. Meas. Tech., 2015, 8, 2397-2408.

60 M. D. Ediger and J. A. Forrest, Macromolecules, 2014, 47, 471-478.

61 W. J. Massman, Atmos. Environ., 1998, 32, 1111-1127.

62 M. Shiraiwa, et al., Nat. Chem., 2011, 3, 291-295.

63 J. Vieceli, et al., J. Phys. Chem. B, 2005, 109, 15876-15892.

64 S. Takahama and L. M. Russell, J. Geophys. Res.: Atmos., 2011, 116, D02203.

65 J. Julin, et al., J. Phys. Chem. A, 2013, 117, 410-420.

66 M. Shiraiwa, et al., Atmos. Chem. Phys., 2014, 14, 8323-8341.

67 G. D. Smith, et al., J. Phys. Chem. A, 2002, 106, 8085-8095.

68 J. D. Hearn, A. J. Lovett and G. D. Smith, Phys. Chem. Chem. Phys., 2005, 7, 501-511.

69 S. S. Steimer, et al., Atmos. Chem. Phys., 2014, 14, 10761-10772. 70 D. R. Hanson, A. R. Ravishankara and S. Solomon, J. Geophys. Res.: Atmos., 1994, 99, 3615-3629.

71 T. Murata, M. S. Lee and A. Tanioka, J. Colloid Interface Sci., 1999, 220, 250-254.

72 H. C. Price, et al., Chem. Sci., 2015, 6, 4876-4883.

73 E. Mikhailov, et al., Atmos. Chem. Phys., 2009, 9, 9491-9522.

74 R. Sander, Atmos. Chem. Phys., 2015, 15, 4399-4981.

75 S. D. Razumovskii and G. E. Zaikov, Ozone and its reactions with organic compounds, Elsevier, Amsterdam, 1984.

76 A. K. Bin, Ozone: Sci. Eng., 2006, 28, 67-75.

77 J. Hoigne and H. Bader, Water Res., 1983, 17, 173-183. 
78 P. J. Gallimore, et al., Atmos. Chem. Phys., 2011, 11, 12181-12195.

79 C. W. Dilbeck and B. J. Finlayson-Pitts, Phys. Chem. Chem. Phys., 2013, 15, 1990-2002.

80 A. Maranzana, et al., J. Phys. Chem. A, 2005, 109, 10929-10939. 81 U. Pöschl, et al., J. Phys. Chem. A, 2001, 105, 4029-4041.

82 L. Vereecken, D. R. Glowacki and M. J. Pilling, Chem. Rev., 2015, 115, 4063-4114.

83 E. R. Altwicker and J. Basila, Tetrahedron, 1973, 29, 1969-1974.

84 W. G. Alcock and B. Mile, J. Chem. Soc., Chem. Commun., 1976, 5-6, DOI: 10.1039/c39760000005.
85 M. Olzmann, et al., J. Phys. Chem. A, 1997, 101, 9421-9429. 86 C. A. Taatjes, D. E. Shallcross and C. J. Percival, Phys. Chem. Chem. Phys., 2014, 16, 1704-1718.

87 K. T. Kuwata, et al., J. Phys. Chem. A, 2010, 114, 9192-9204. 88 C. R. Usher, A. E. Michel and V. H. Grassian, Chem. Rev., 2003, 103, 4883-4940.

89 J. McCabe and J. P. D. Abbatt, J. Phys. Chem. C, 2009, 113, 2120-2127.

90 S. Enami, M. R. Hoffmann and A. J. Colussi, Proc. Natl. Acad. Sci. U. S. A., 2008, 105, 7365-7369. 